\title{
Proceso de elaboración de cartografía táctil para ciegos y débiles visuales
}

\author{
J. Jesús Villalpando Esparza*
}

Recibido el 15 de julio de 2014; aceptado el 1 de agosto de 2014

\begin{abstract}
Tactile cartography, with writing in Braille, enables the blind and the visually handicapped to strengthen their knowledge of geography and capture new geo-information through their sense of touch. This article presents the process used for making and thermoforming tactile geographic maps at the General Geography and Environment Management, part of the National Institute for Statistics and Geography (INEGI) of Mexico. The process covers the stages of editing the map information, sketching out the map graphically, editing the vertical element in the terrain portrayal, the shaping of the terrain and its heights, making a model in plasticine, setting up the initial moulds in plaster and /or latex, cutting and shaping the edges, creating the final mould in resin, thermo-shaping the map, making and attaching the lettering. Moreover, recommendations are given for aiding the reading, interpretation and comprehension of a tactile map, and finally a catalogue of maps made by the institution is described and shown.
\end{abstract}

Key words: Tactile cartography, Braille maps, tactile maps.

\section{Resumen}

La cartografía táctil con su escritura en Braille, permite a los ciegos y débiles visuales reforzar y captar los conocimientos de la información geográfica a través del tacto. En este artículo se presenta el proceso utilizado para la elaboración y termoformado de los mapas geográficos táctiles en la Dirección General de Geografía y Medio Ambiente, del Instituto Nacional de Estadística y Geografía de México (INEGI), el cual comprende las etapas de edición de la información del mapa, graficación, edición de alturas del terreno, corte y conformación de formas, altura del terreno, modelado en plastilina, obtención de contramoldes en yeso y/o látex, perfilado y desbaste, obten-

Instituto Nacional de Estadística y Geografía (INEGI), Avenida Héroe de Nacozari Sur 2301, Fraccionamiento Jardines del Parque, 20276, Aguascalientes, Ags., México, correo electrónico: Jesus.villalpando@inegi.org.mx 
ción del molde en resina, termoformado del mapa, elaboración y pegado de tipografía, también se dan recomendaciones para apoyar la lectura, interpretación y comprensión de un mapa táctil, finalmente se relaciona y muestra un catálogo de los mapas elaborados en la institución.

Palabras clave: Cartografia táctil, mapas Braille, mapas táctiles.

\section{Resumo}

A cartografia tátil, com seu sistema de escrita braile, permite aos cegos e às pessoas com baixa visão reforçarem e captarem os conhecimentos da informação geográfica por meio do tato. Neste artigo, apresenta-se o processo utilizado para a elaboração e termoformação dos mapas geográficos táteis na Direção Geral de Geografia e Meio Ambiente, do Instituto Nacional de Estadística e Geografia do México (INEGI), que compreende as etapas de edição da informação do mapa, colocação do mapa em gráfico, edição de alturas do terreno, corte e conformação de formas e de altura do terreno, modelagem em plastilina, obtenção de contramoldes em gesso e/ou látex, perfilado e desbastamento, obtenção da fôrma em resina, termoformação do mapa, elaboração e adesão de tipografia; além disso, fazem-se recomendações para apoiar a leitura, interpretação e compreensão de um mapa tátil e, finalmente, relaciona-se e mostra-se um catálogo dos mapas elaborados na instituição.

Palavras-chave: Cartografia tátil, mapas braile, mapas táteis.

\section{Introducción}

El presente artículo tiene el objetivo de dar a conocer el procedimiento y actividades que se desarrollan en la Dirección General de Geografía y Medio Ambiente del Instituto Nacional de Estadística y Geografía (INEGI), para elaborar mapas táctiles que apoyen la impartición de conocimientos geográficos a personas ciegas y débiles visuales.

La técnica de termoformado para mapas táctiles, permite la producción de grandes volúmenes de mapas en tiempo relativamente corto, la técnica comprende las tareas de edición, impresión, corte y conformación de alturas, el modelado del terreno en plastilina, y la elaboración del contramolde, tareas importantes en la producción de cartografía táctil, porque de ellas depende la calidad del molde donde se termoforma el mapa y en el desarrollo de ellas se requiere de conocimientos y habilidades específicas, para tener un molde bien elaborado que refleje los rasgos del terreno a la escala de representación, además de que tenga la dureza y resistencia para aguantar el calor y succión del vacío durante el termoformado.

El contar con impresoras Braille en la institución cartográfica, facilita la impresión de la tipografía y rotulación de los rasgos del terreno en escritura Braille, obteniéndose un texto de calidad que ayuda a la persona ciega a la lectura de la información del mapa. Asimismo, la elaboración de los mapas táctiles en color y letra 
visual, así como letra en Braille, permite al profesor, padres de familia, compañeros y amigos del usuario, apoyarle en la enseñanza y ampliar la interacción y fortalecimiento de los conocimientos geográficos; para guiar al niño en el uso del mapa táctil, se sugiere que el profesor y los padres conozcan de forma básica la temática, los elementos y la información marginal de los mapas para que se facilite la explicación del contenido y significado de los símbolos que la persona invidente percibirá mediante el tacto.

Los mapas táctiles elaborados en el INEGI, son muy básicos y generales para apoyar la impartición de la geografía en los niveles escolares de la primaria y secundaria, son mapas fáciles de interpretar y utilizar. Actualmente no se cuenta con datos estadísticos que indiquen el grado de aceptación de los mapas producidos, sin embargo durante su elaboración, se recibe apoyo de profesores de escuelas primarias que tienen a cargo alumnos ciegos, quienes hacen recomendaciones que se consideran en el diseño y representación de la información en alto y bajo relieve. Los mapas han llamado la atención por su temática y su terminación.

\section{Proceso de elaboración de mapas táctiles}

La representación de la información del relieve del terreno, de los ríos y cuerpos de agua, del clima, de la vegetación, los suelos, los fenómenos geográficos como ciclones, sismos, tornados, entre otros; así como de la traza y referencia de las ciudades urbanas y rurales, se plasma en los mapas táctiles, realizando el procedimiento cartográfico que es detallado a lo largo de este artículo.

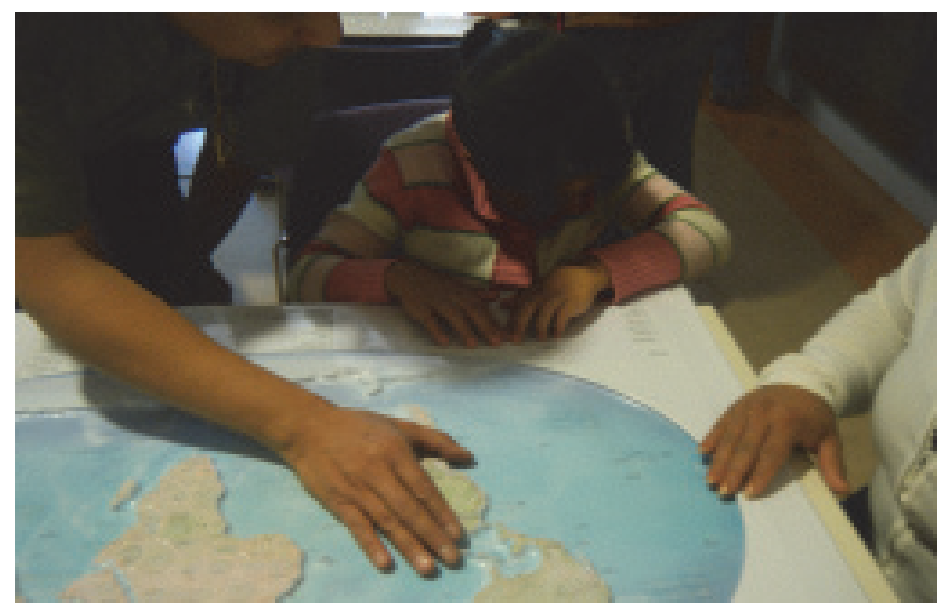

Figura 1. Profesor trabajando con mapas geográficos táctiles. 


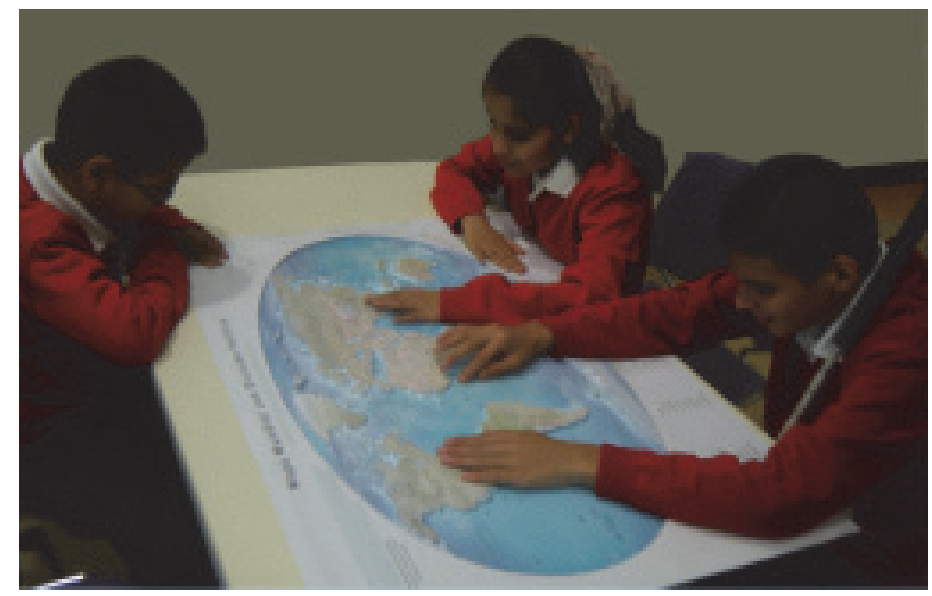

Figura 2. Alumnos trabajando con mapas geográficos táctiles.

\section{Edición de la información}

En una primera fase los rasgos y elementos geográficos son editados en computadoras bajo las normas cartográficas de la institución para obtener un archivo digital del mapa en formato .pdf, este es impreso en plotter o imprenta offset en material PVC, que es termoformado obteniendo líneas, formas y texturas en alto y bajo relieve, diferenciándose estas mediante el tacto de los dedos de la mano por las personas ciegas. En una segunda fase el mapa es diseñado teniendo en cuenta el espaciado necesario entre los elementos representados, ya que la tipografía de las referencias geográficas en escritura Braille es mucho más extensa que la escritura de los mapas visuales, por lo que es muy importante seleccionar la información que se representará en el mapa. En el siguiente ejemplo se muestra la diferencia de espacio que ocupa la escritura Braille en relación a la escritura del alfabeto español.

Río Coatzacoalcos

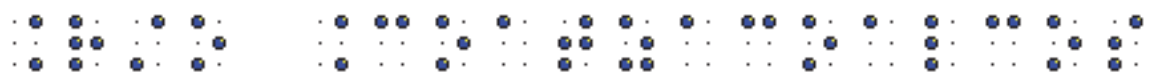

En los mapas se evita el uso de solo mayúsculas para optimizar los espacios e incluir más tipografía para enriquecer el mapa.

La información en el mapa táctil se representa con símbolos que han sido elegidos para los rasgos geográficos, símbolos que facilitan su identificación mediante el tacto, usando los dedos de la mano. En la selección de símbolos es importante que se consulte al personal del taller de termoformado para tener puntos de vista que puedan interferir en la elaboración del molde. 
El mapa se realiza en color, aún cuando las personas ciegas no lo perciban, pero si podrá ser de gran ayuda para los débiles visuales, el profesor y las personas que apoyan en el aprendizaje.

Los colores utilizados en los mapas son los mismos que se consideran en los mapas visuales, en donde los colores se "relacionan estrechamente con las sensaciones y estados de ánimo, el verde es frío, el rojo es cálido, el sepia es seco, el azul es húmedo, el amarillo soleado", 1 pero también son los colores que encontramos en la naturaleza, verde en la vegetación, azul en el agua, amarillos y marrones vegetación seca y suelos, o bien mediante la asociación de colores con respecto a las temperaturas, azul y blanco representan al frío, verdes clima templado, rojos y amarillos climas cálidos húmedos y cálidos secos.

\section{Graficación del mapa}

Una vez terminada la edición del mapa, este se grafica vía plotter en papel bond para dar una revisión visual a la información, además de verificar que los rótulos en Braille e información marginal queden en los espacios correspondientes, de haber inconsistencias o ajustes a la información se marcan en el mapa. Al concluir la edición de la información, se grafica y se entrega al taller de termoformado.

\section{Edición de alturas del terreno}

En los mapas táctiles, si se va a representar la orografía del terreno, adicionalmente a la edición de los rasgos, se editan por separado las curvas de nivel o tintas hipso-

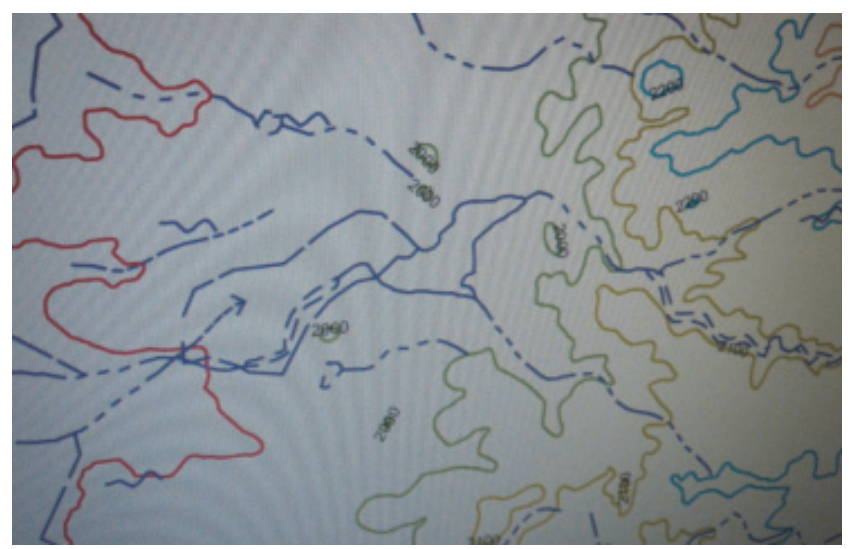

Figura 3. Curvas de nivel editadas y graficadas en plotter, adicional a las curvas se indican las corrientes de agua.

1 Arthur H. Robinson, Randall D. Sale, Joel L. Morrison, Phillip C. Muehrcke; Elementos de Cartografia, Ed. Omega, Barcelona, España, 1987. 
gráficas del terreno y las corrientes de agua, asignando colores diferentes a las curvas de nivel o bien utilizando tintas de diferentes colores para la hipsografía, esto permite diferenciar rangos de las alturas del relieve y facilita su control durante el corte y conformación de alturas, las corrientes de agua facilitan el modelado del terreno en plastilina.

Al finalizar la edición de alturas del terreno, éstas se grafican en plotter y se entregan al taller de termoformado, allí se realizarán los cortes y se conformará el modelo del terreno.

Si en el mapa no se representan las alturas del terreno, se grafica el mapa editado y se entrega al taller de termoformado para realizar el perfilado y desbastado para obtener un contramolde.

\section{Corte, conformación de formas y altura del terreno}

Sobre la impresión de las curvas de nivel o las tintas de alturas del terreno, con una cortadora de sierra cinta o router para madera, se van cortando las capas que tienen la misma altitud, seguidamente se enciman y pegan en el orden de menor a mayor altura.
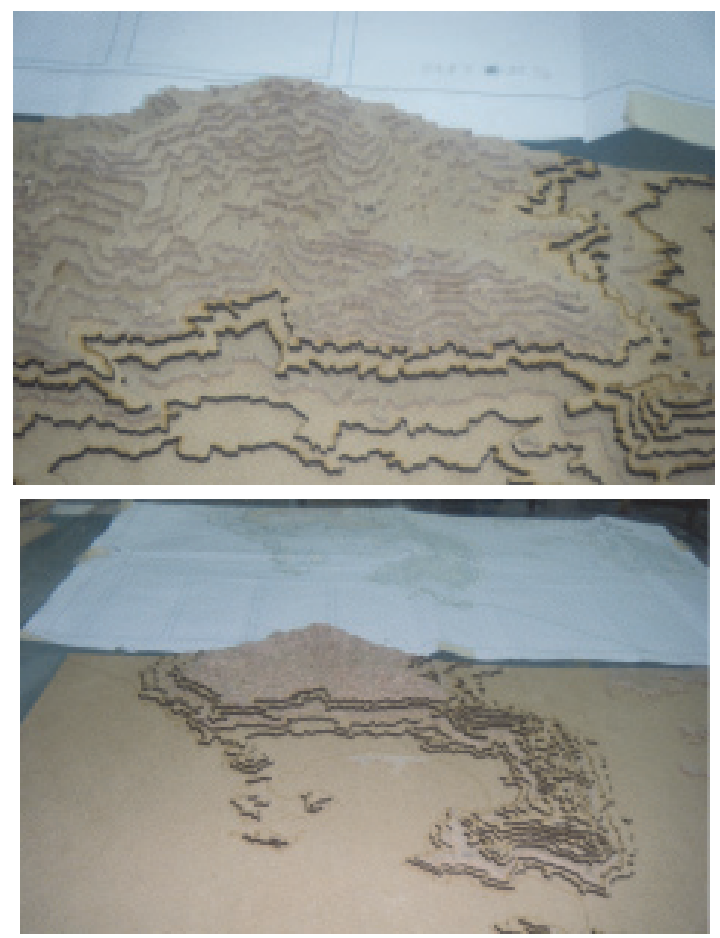

Figuras 4 y 5. Corte de alturas en capas sobre mdf (madera aglomerada). 


\section{Modelado en plastilina}

Posteriormente las alturas y formas del terreno se modelan con plastilina para obtener el prototipo matriz que servirá para generar el contramolde, el modelado requiere de conocimientos para analizar e interpretar las formas y pendientes del terreno y habilidades artísticas sobre modelado con plastilina, porque de ello depende que en el termoformado registren los rasgos impresos en el molde elaborado en resina.

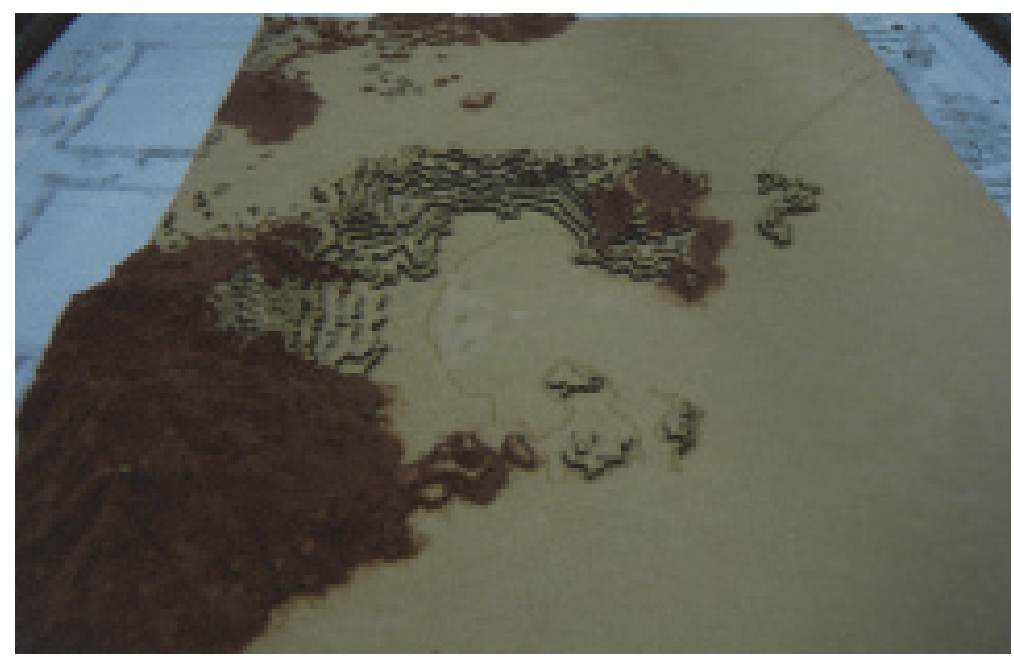

Figura 6. Modelado del terreno.

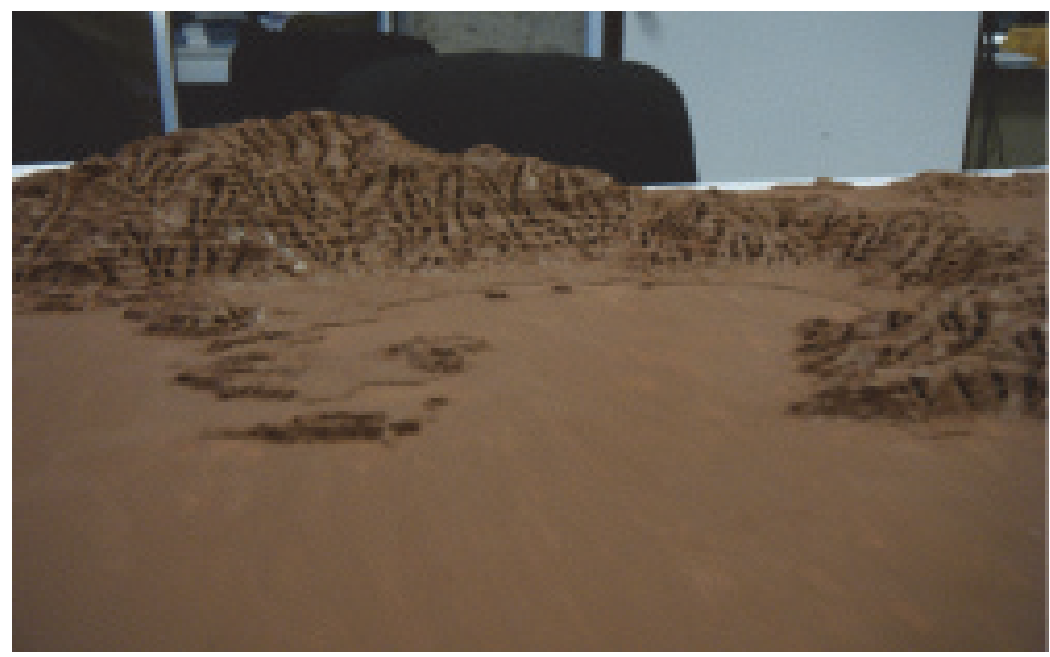

Figura 7. Prototipo matriz en plastilina. 


\section{Obtención de contramoldes en yeso y/o látex}

Previo a la obtención del molde para termoformar el mapa, se requiere de un prototipo o contramolde, en él se vierte la resina (material resistente al calor y succión de la máquina de vacío), para la obtención de este contramolde; el prototipo en plastilina se encajona, se le vacía yeso, una vez fraguado se desmolda y se detallan las imperfecciones.

Si se requiere conservar un contramolde, en lugar de la pasta de yeso se vierte látex, más una o dos láminas de fibra de vidrio, misma que dará soporte al látex para cuando se esté utilizando en el vaciado de resina.

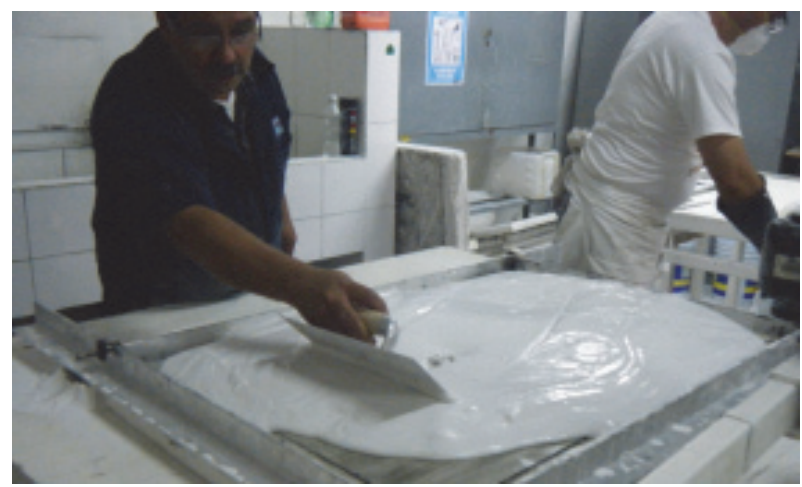

Figura 8. Vaciado de yeso para elaborar contramolde.

\section{Perfilado y desbaste}

Los mapas que no representarán la orografía, se grafican en plotter, impresora láser o de inyección de tinta, dependiendo del tamaño del mapa, con éste se realiza el tras-

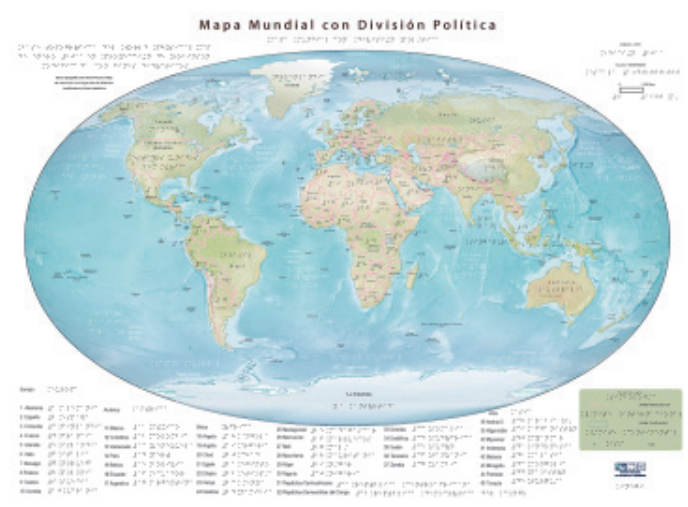

Figura 9. Mapa mundial sin orografía. 
paso de información al material que servirá de prototipo matriz para el contramolde, el material puede ser yeso, madera, cartón para trabajos arquitectónicos, barro o cera de abeja.

En la Figuras 10 y 11 se ejemplifica el traspaso de líneas, formas, y áreas de la información del mapa táctil, sobre laminados de madera, de cartón, barro, cera, y yeso (escayola).

Si los rasgos fueron transferidos directamente en yeso, sobre las líneas y formas, se realiza el desbastado y perfilado con una gurbia, taladro, pantógrafo eléctrico, espátula filosa u otro objeto de desbaste, detallando la profundidad de lo alto y bajo relieve, en este proceso se obtiene directamente el contramolde donde se vaciará la resina.

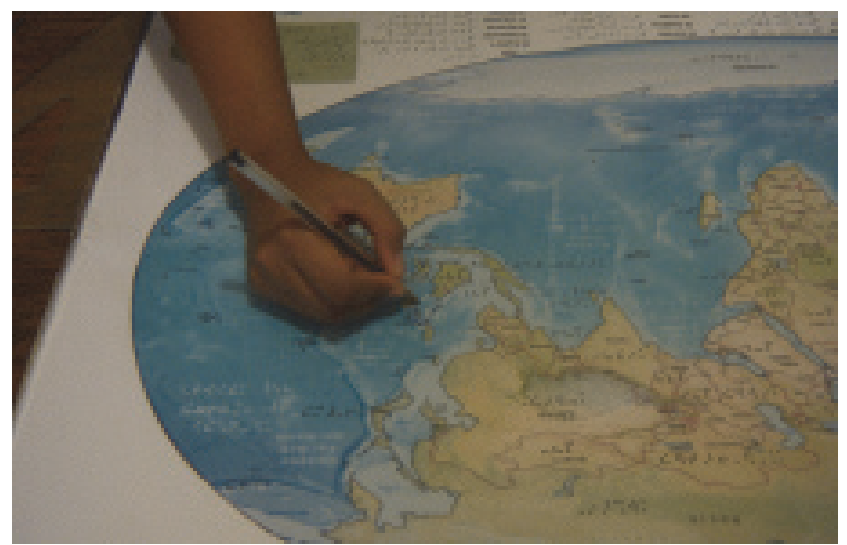

Figura 10. Traspaso de rasgos de forma manual utilizando papel pasante.

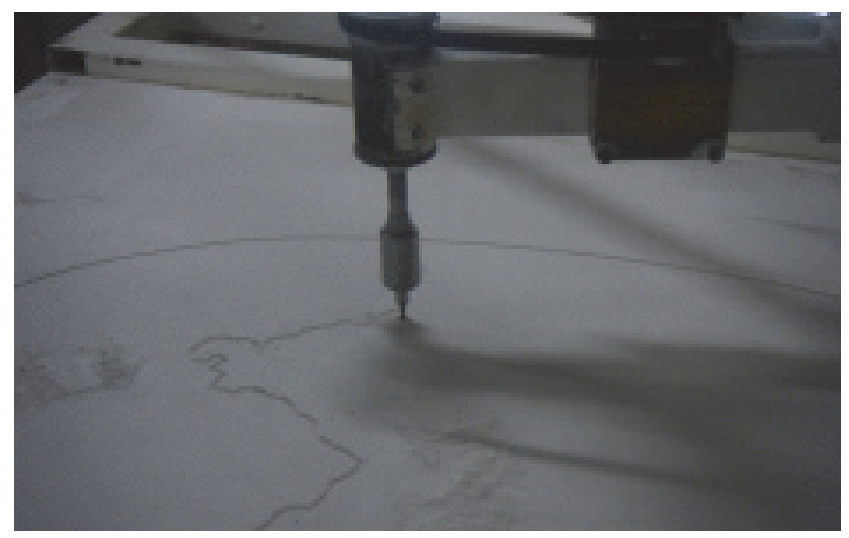

Figura 11. Transferencia de forma y rasgos a la placa de yeso, utilizando un pantógrafo mecánico. 
Si se trabaja en otros materiales como madera mdf, cartón para trabajos arquitectónicos, barro o cera de abeja, se perfilan las líneas, formas, símbolos a representar, se cubren de pintura vinílica y grasa desmoldante, excepto la cera ya que este material por sus características no se adhiere, y se elabora un contramolde en yeso, bajo el procedimiento de obtención de contramoldes en yeso y/o látex.

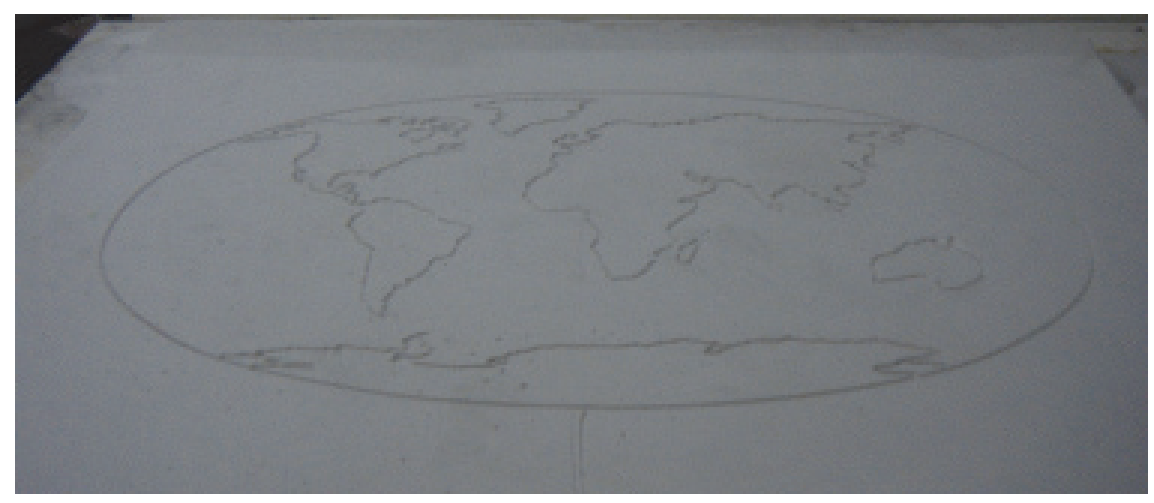

Figura 12. Perfilado.

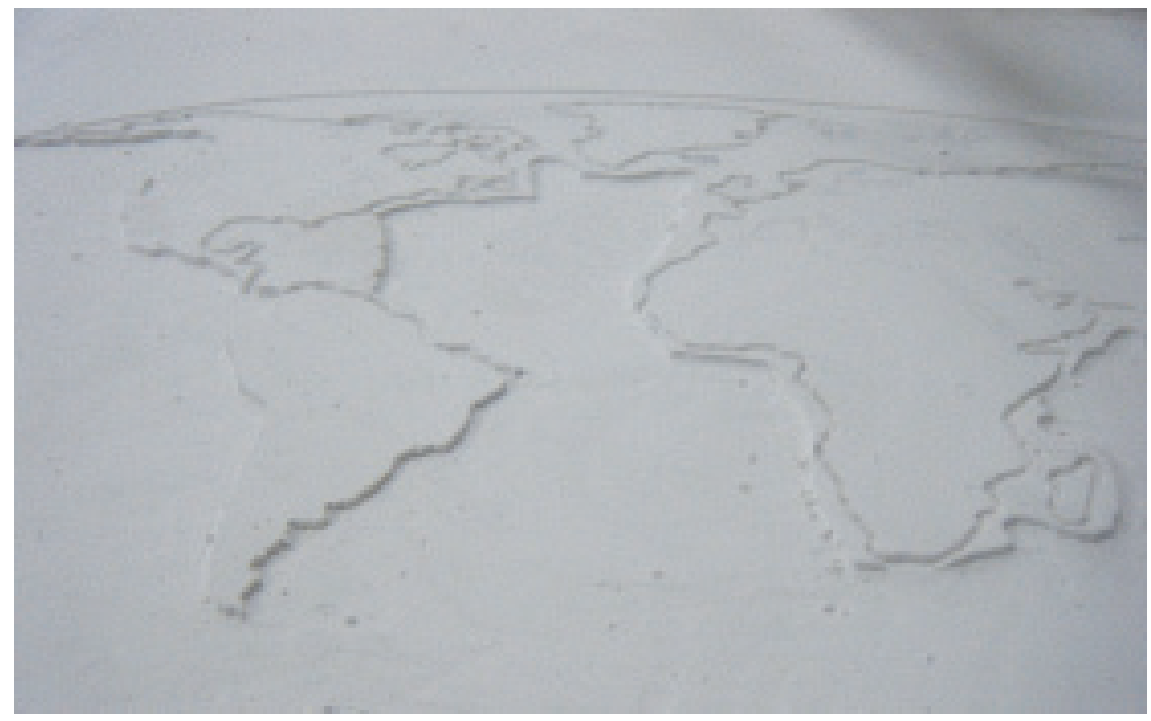

Figura 13. Desbastado de material sobrante. 


\section{Molde en resina}

Una vez que se cuenta con los contramoldes, pintados y engrasados, se encajonan y se fija bien la placa de yeso para verter la pasta de resina.

Se prepara la resina mezclando la pasta y el catalizador, se revuelve bien hasta que la mezcla quede uniforme y se vierte lentamente en el cajón y contramolde para que no agarre burbujas de aire, en la parte superior se incorpora una o dos láminas de fibra de vidrio para una mayor resistencia de la placa del molde de resina.

Al siguiente día la placa del molde de resina estará dura y se procederá a desmoldar, retirando la placa de yeso o desmoldando el látex, según el proceso utilizado.

Se lija el molde para quitarle aristas filosas, se resanan las imperfecciones que sean visibles con plastilina epóxica, y se hacen orificios en las partes bajas con un taladro y una broca de $1 / 16$ y $1 / 32$, para permitir la succión del aire mediante el equipo de vacío durante el termoformado del mapa, quedando el molde listo para utilizarlo en la termoformadora.

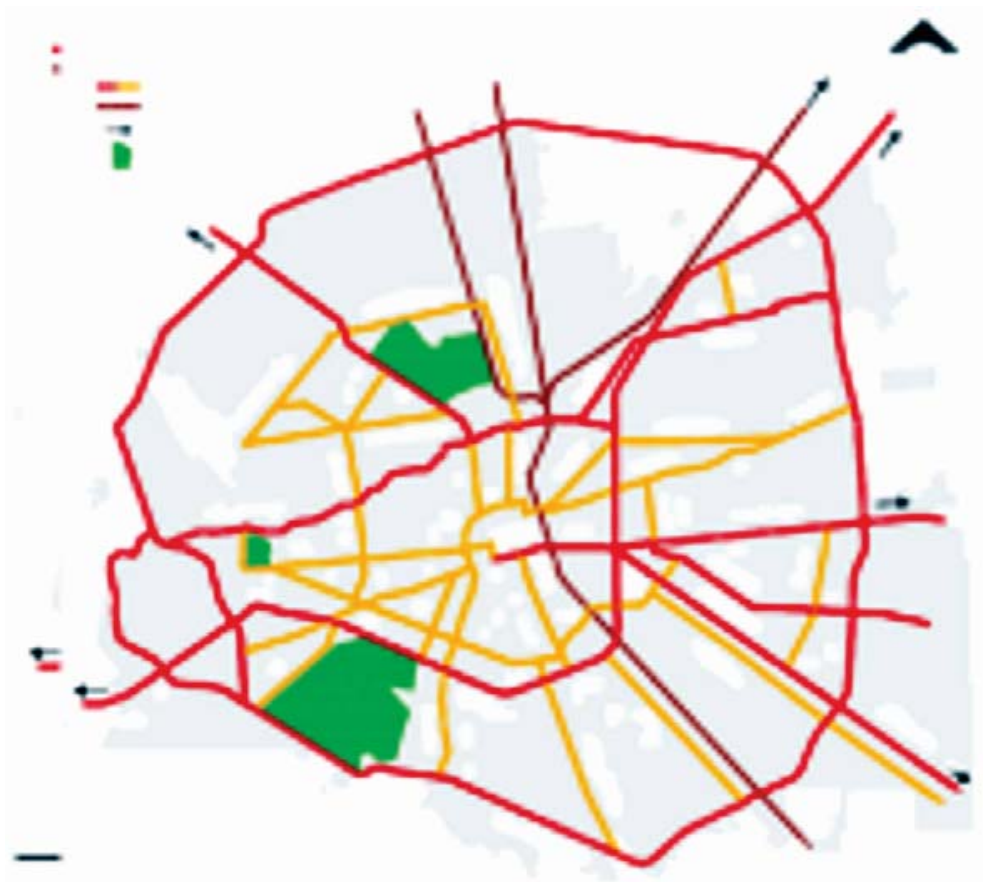

Figura 14. Rasgos en relieve, utilizando cartón para trabajos arquitectónicos. 


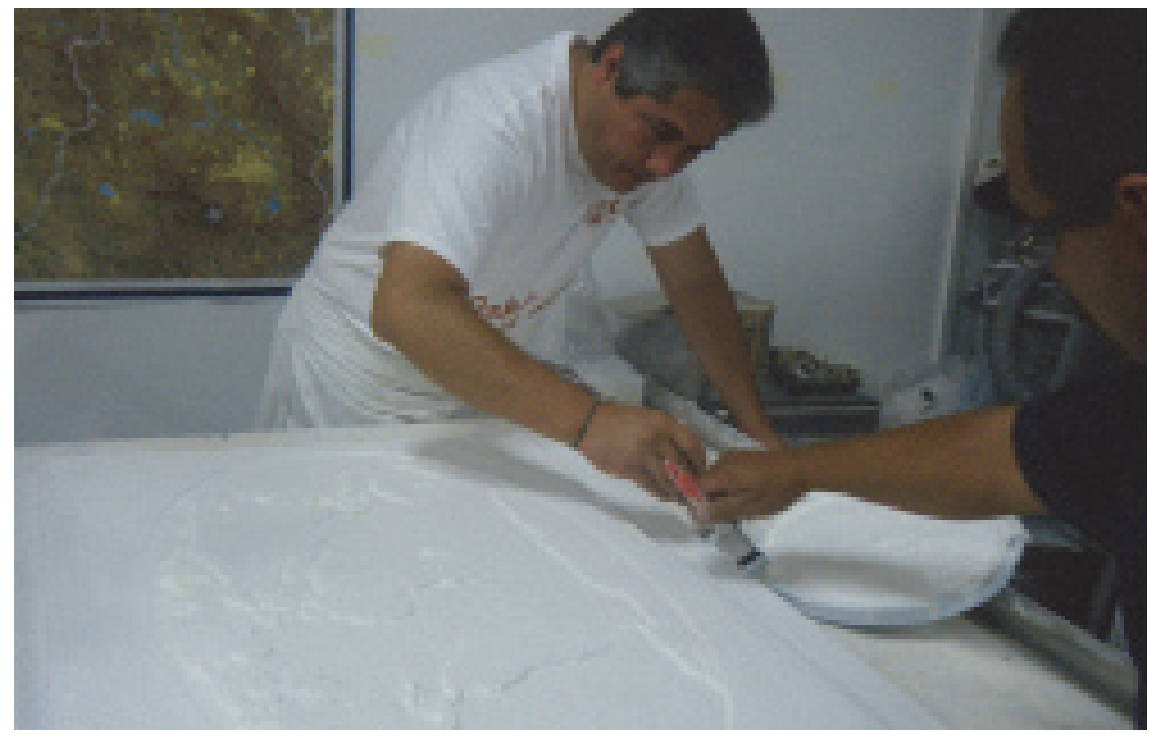

Figura 15. Aplicación de pintura vinílica contramolde.

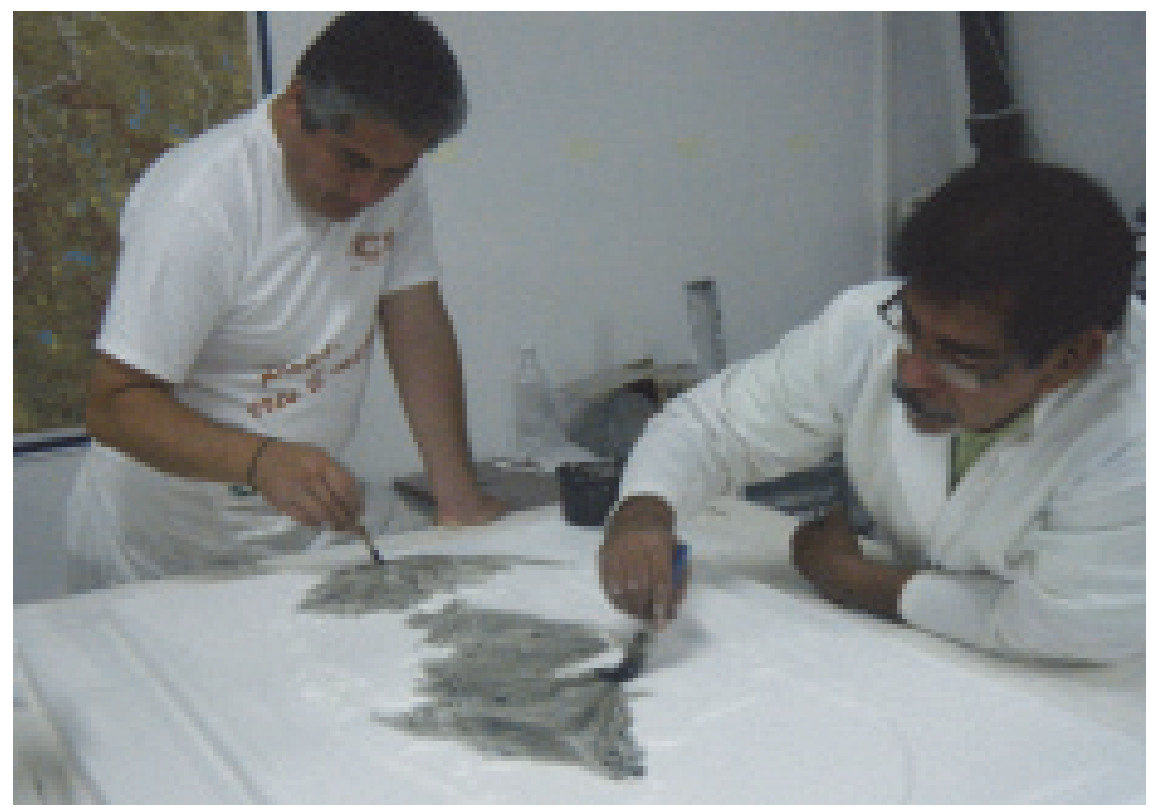

Figura 16. Aplicación de grasa al contramolde. 


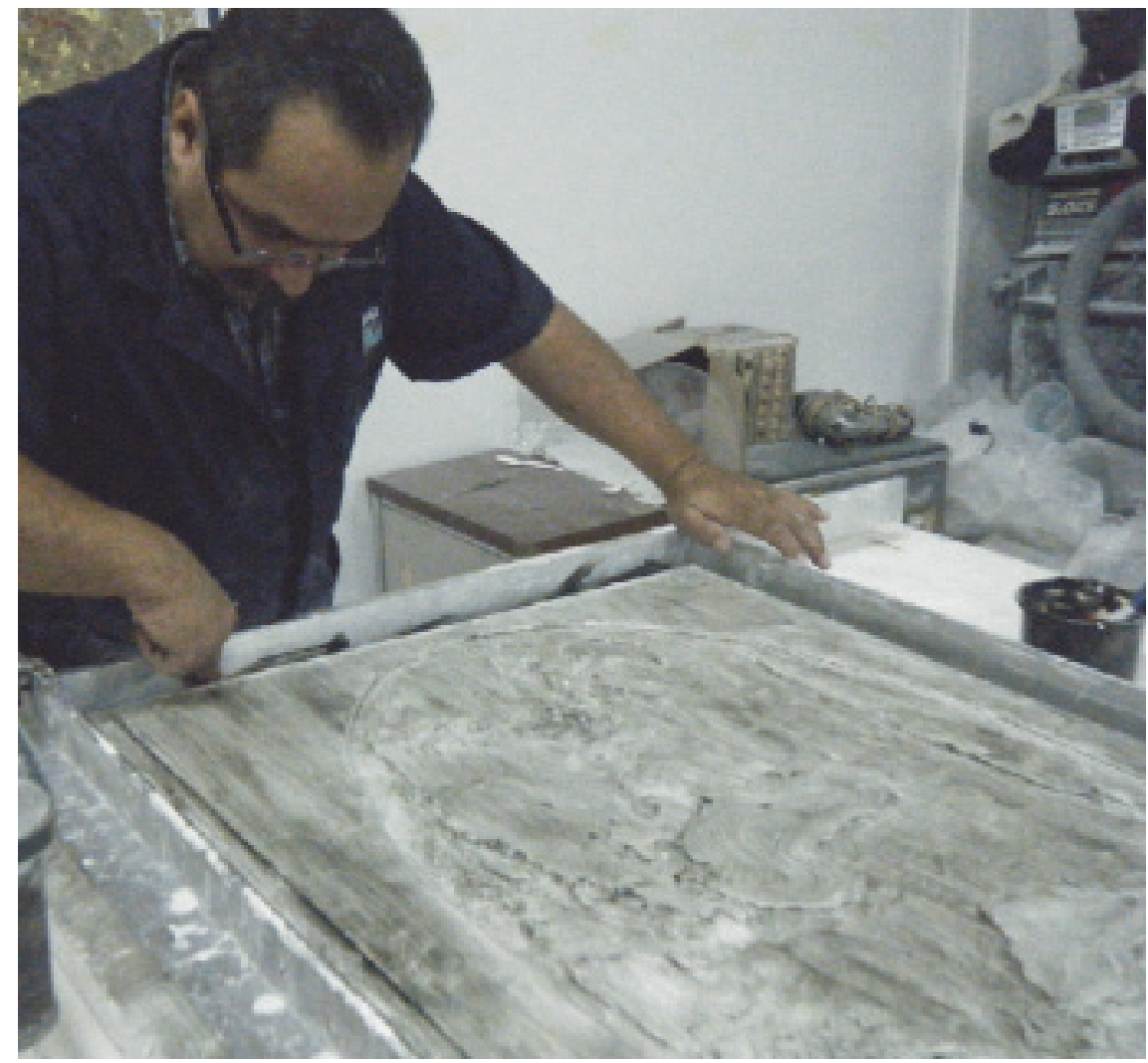

Figura 17. Preparación de molde para vaciar resina.

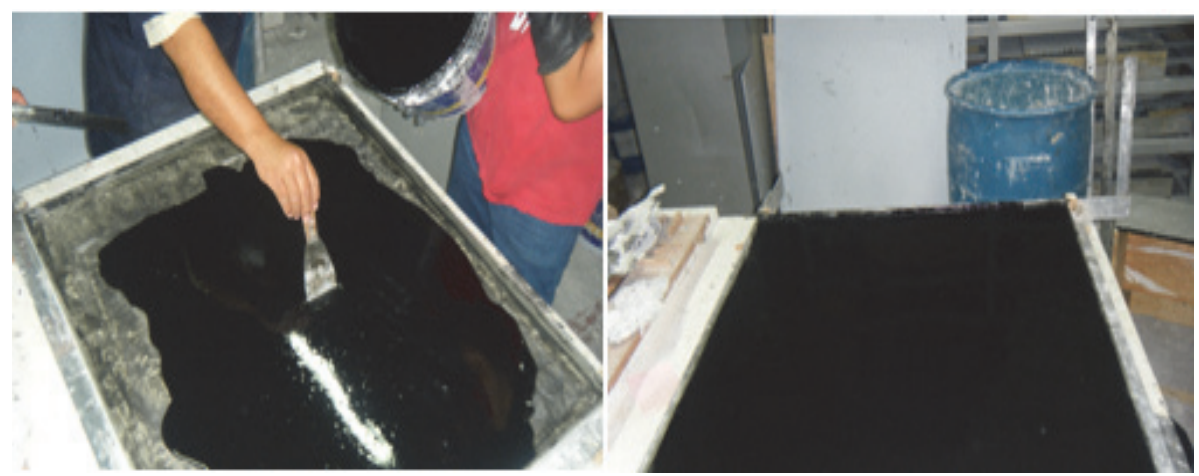

Figura 18. Vaciado de la resina para obtener el molde donde se termoforma el mapa. 


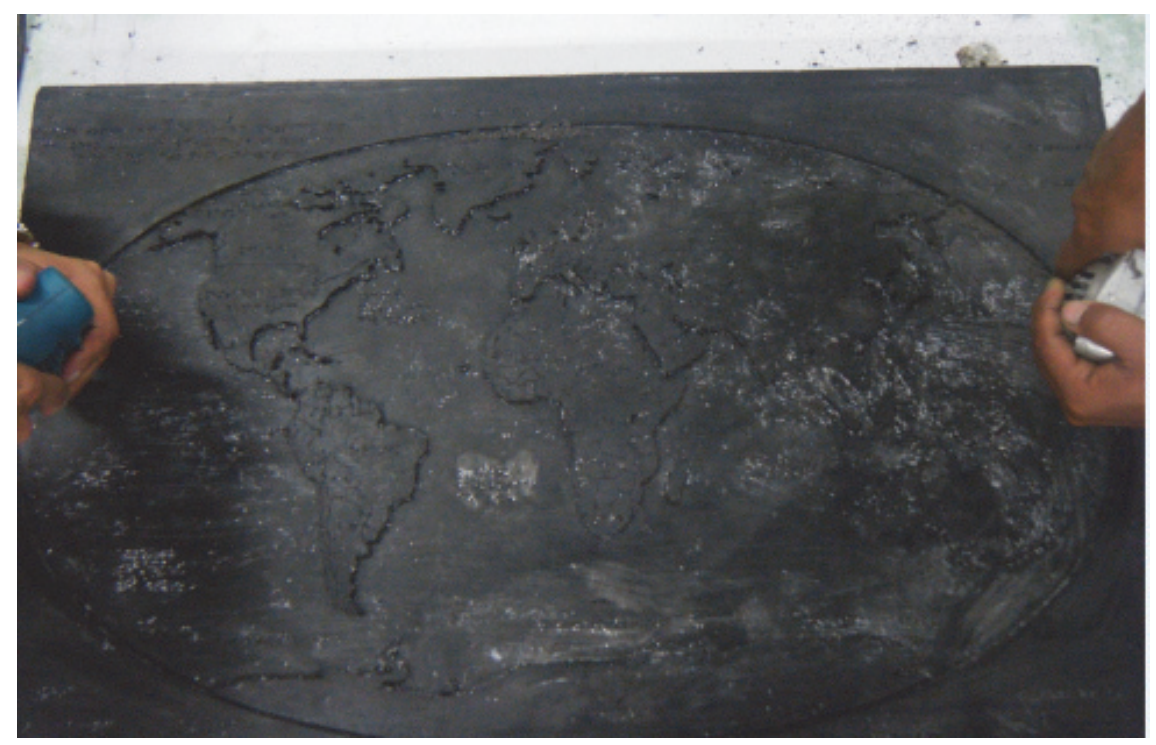

Figura, 19. Molde de resina.

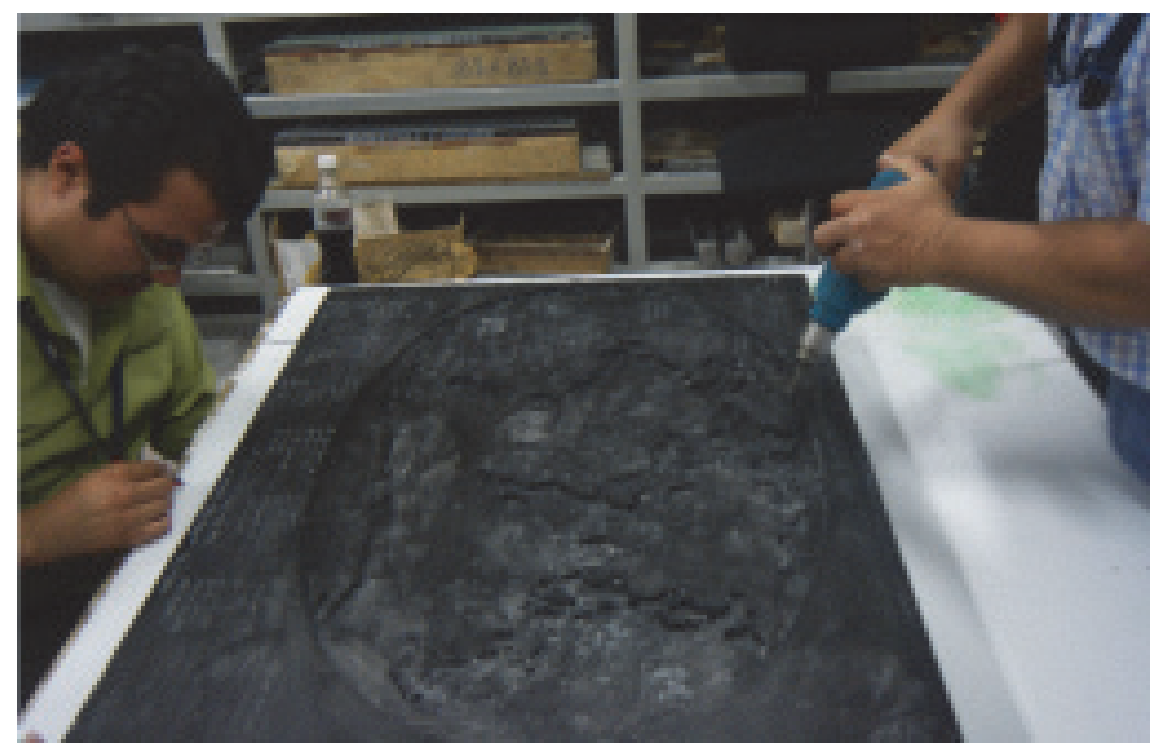

Figura 20. Lijado de aristas y resane de imperfecciones. 


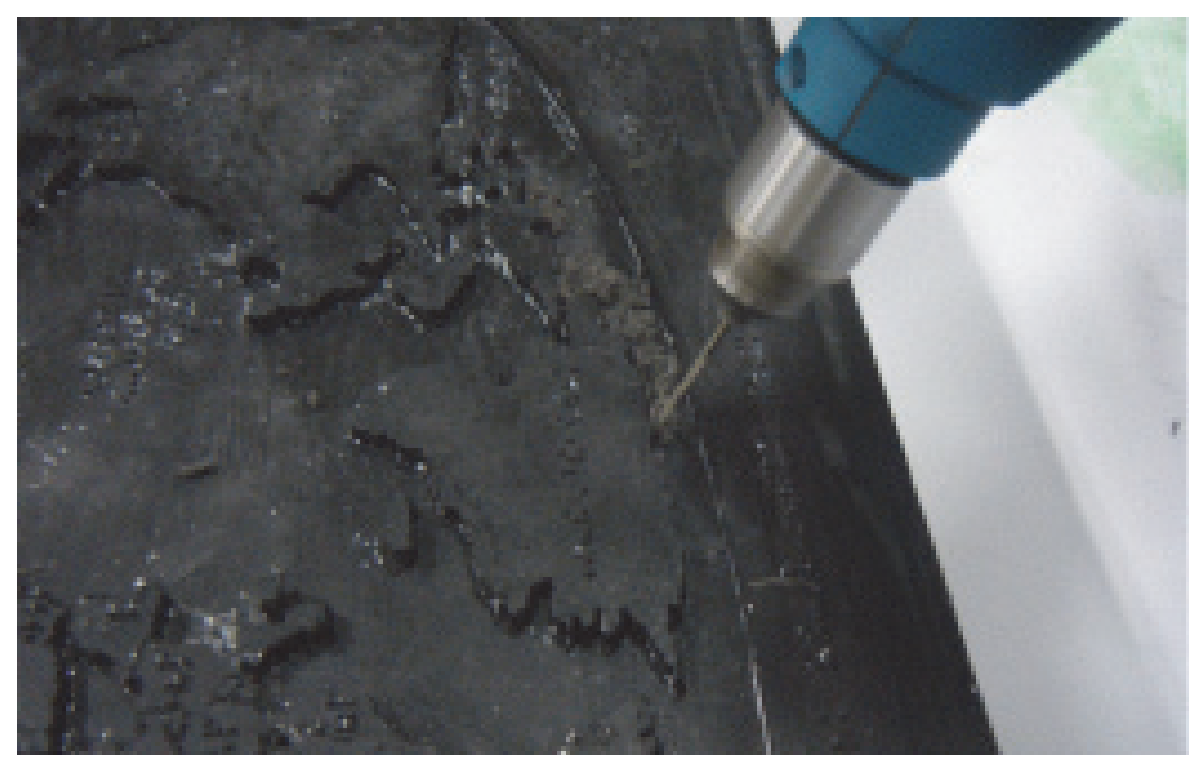

Figura 21 Perforación de orificios para succión de aire.

\section{Termoformado}

El termoformado es un proceso que consiste en dar forma a una lámina plástica por medio de calor radiado entre $120^{\circ} \mathrm{C}$ y $170^{\circ} \mathrm{C}$, aplicando vacío de 600 a $760 \mathrm{mmHg}$, durante 20 segundos de tiempo aproximado, utilizando un molde o matriz en el equipo termoformador.

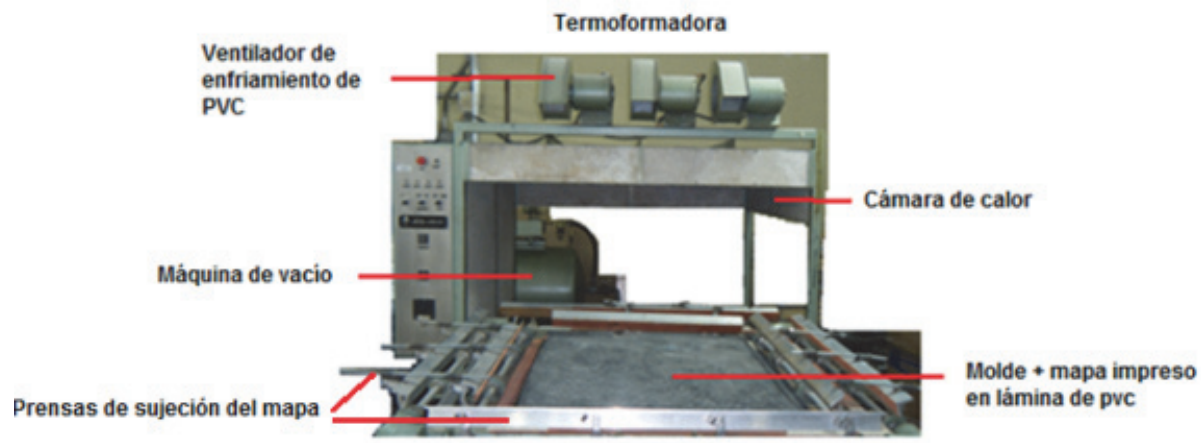

Figura 22. Partes de la termoformadora. 


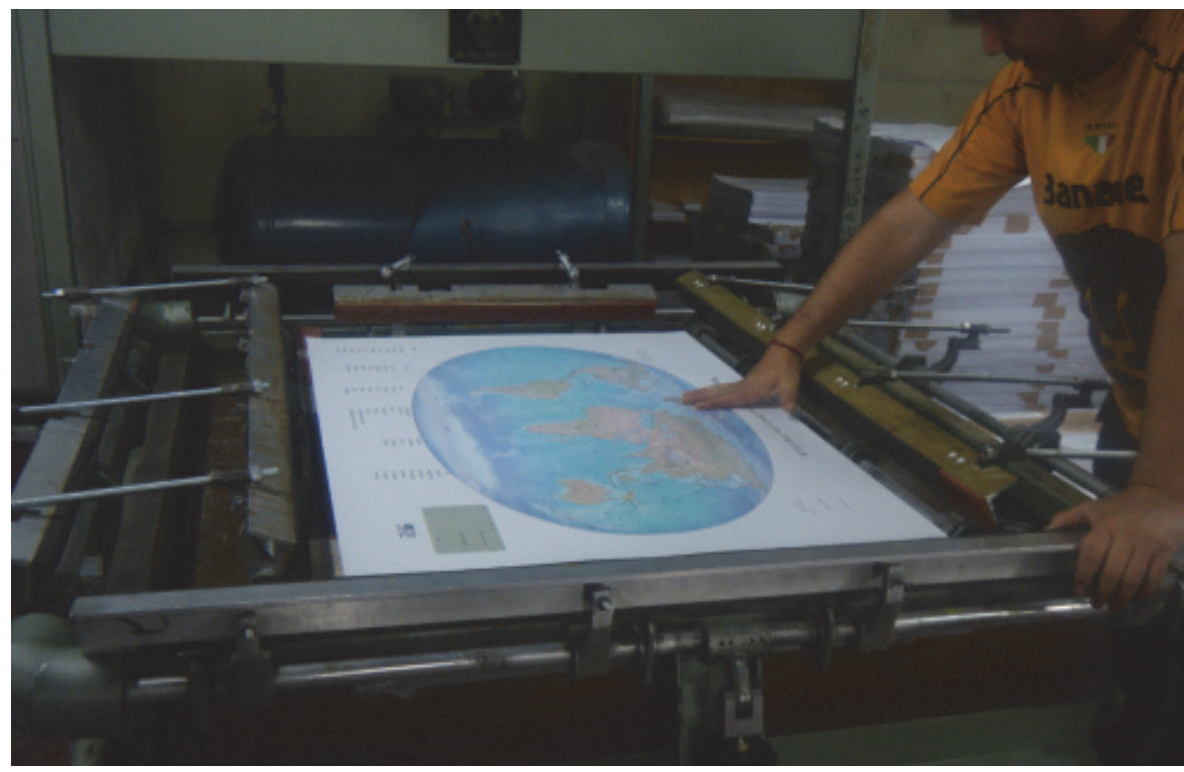

Figura 23. Registro de rasgos del mapa y el molde mediante las alturas del molde.

En la producción de la cartografía táctil se calienta el mapa impreso en PVC (Credicart), en un equipo diseñado para este fin, con resistencias eléctricas y que al encenderse producen calor, en él se expone el mapa entre 35 segundos al inicio de la actividad y hasta 15 segundos conforme la cámara de calor y el molde van adquiriendo mayor calentamiento, las termoformadoras para cartografía con que cuenta el (INEGI), fueron diseñadas para la producción de cartografía, ya que es necesario un registro lo más exacto posible entre los rasgos representados en el mapa y el molde.

Una vez encendida la termoformadora se procede a dar forma al mapa, encimándose éste sobre el molde del mapa, registrando los rasgos de las partes altas y bajas entre ambos productos, introduciéndose posteriormente en la cámara de calor, produciéndose un estiramiento y contracción del material, bajando después y ejerciendo una fuerte presión que ajusta el PVC y el molde al ejercer succión del aire de un compresor de vacío, y recibiendo a la vez enfriamiento mediante los ventiladores.

\section{Tipografía}

Al igual que el mapa se elabora en color, también se indica la tipografía visual y la tipografía en Braille, conteniendo esta los títulos y nombres de los rasgos y elementos del mapa para su lectura por medio del tacto de los dedos de la mano, la impresión 


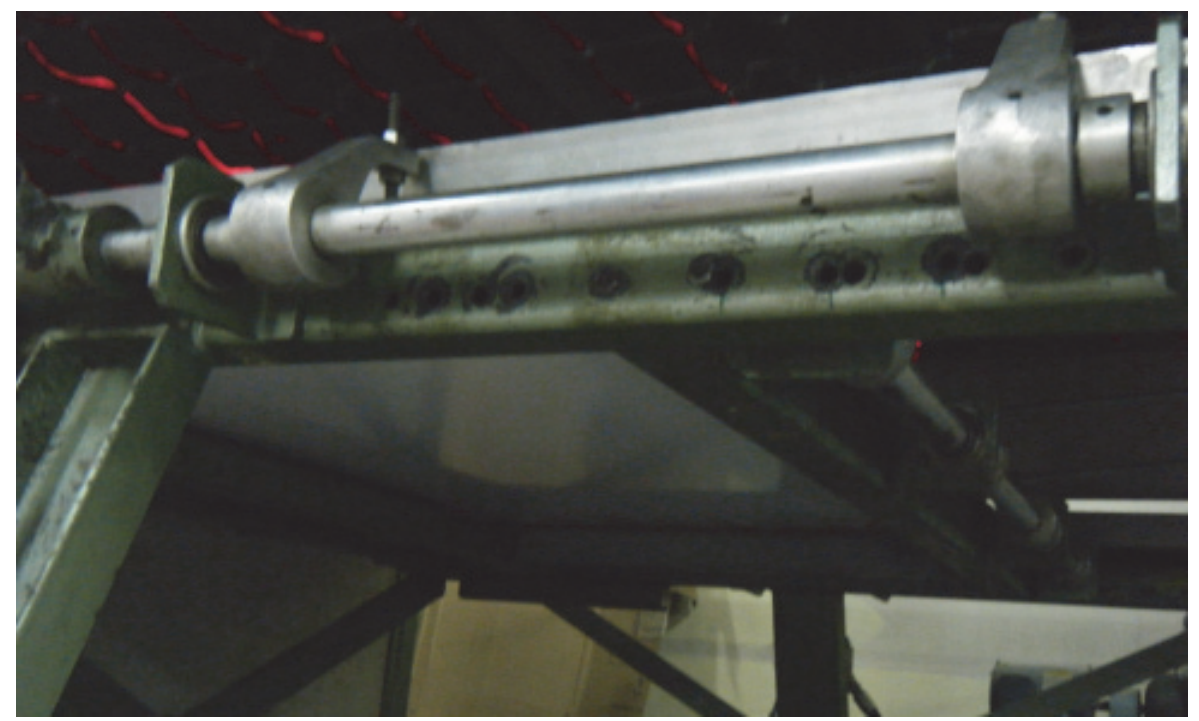

Figura 24. Molde y mapa dentro de la cámara de calor.

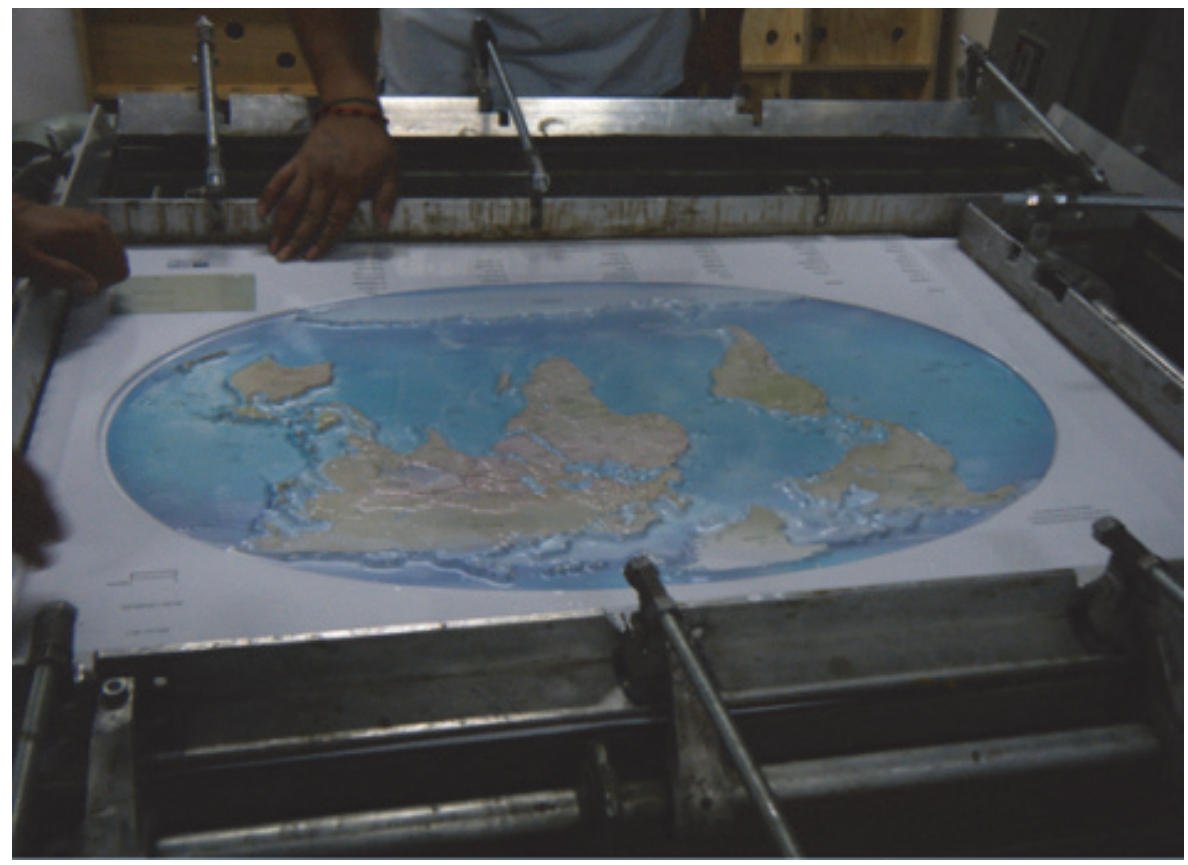

Figura 25. Mapa termoformado. 
del texto se realiza mediante impresoras Braille en mica autoadherible y después se pega sobre el rasgo correspondiente e información marginal del mapa.

La impresión se realiza en papel contact transparente del número 5 , con la finalidad de no bloquear los rasgos del mapa en color. Ejemplo de rótulos:

Golfo de México (letra visual)

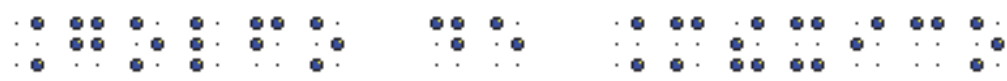

Río Grijalva (letra visual)

(letra Braille)

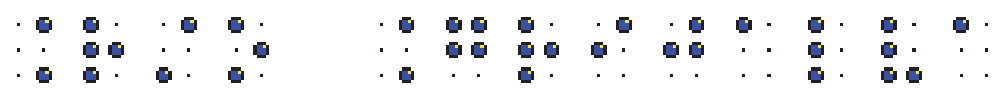

(letra Braille)

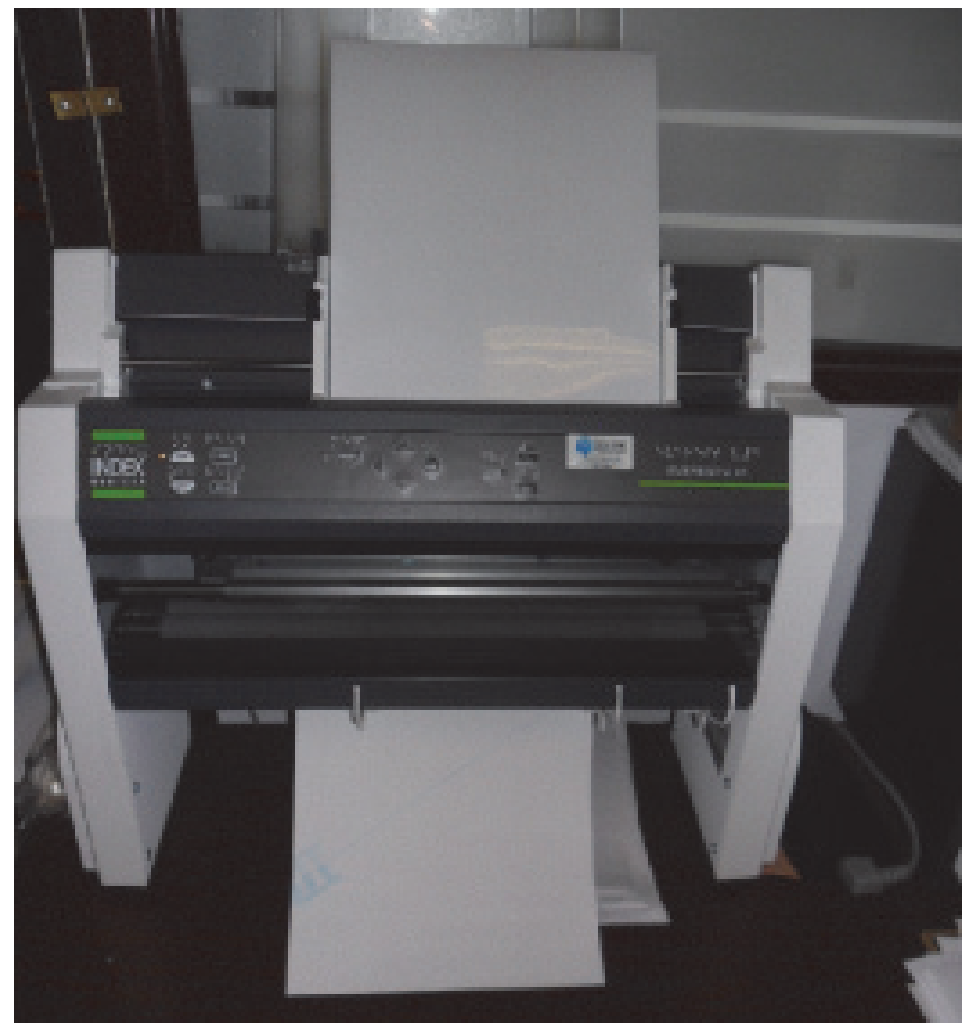

Figura 26. Impresora Braille para rotular texto de los mapas táctiles. 

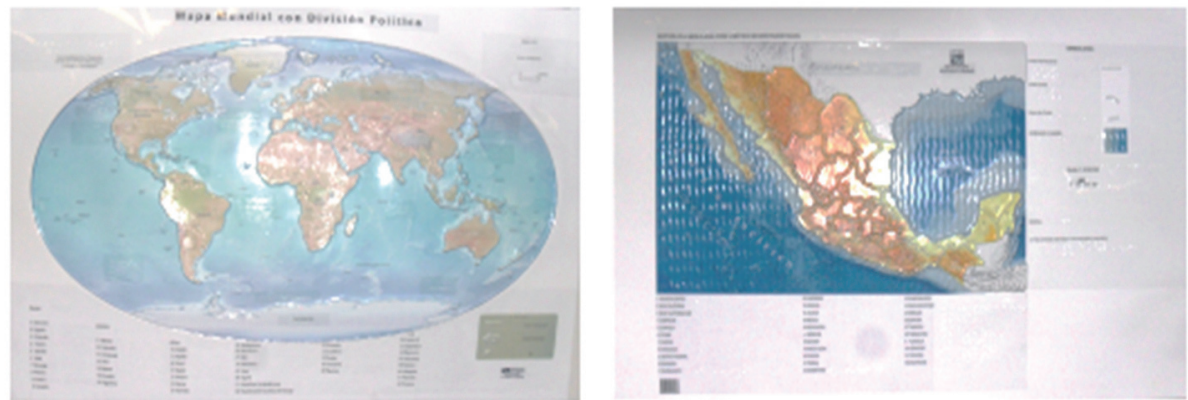

Mapa mundial con división política.

Mapa de límites geoestadísticos.
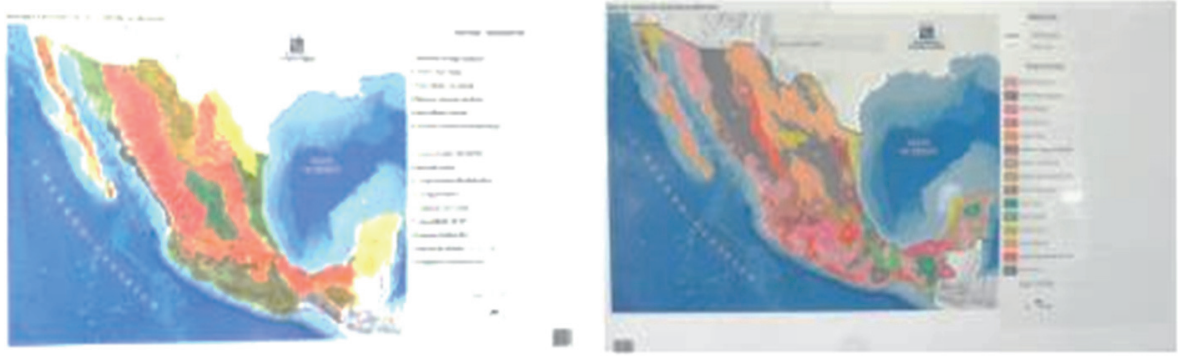

Mapa de regiones fisiográficas.

Mapa de suelos.
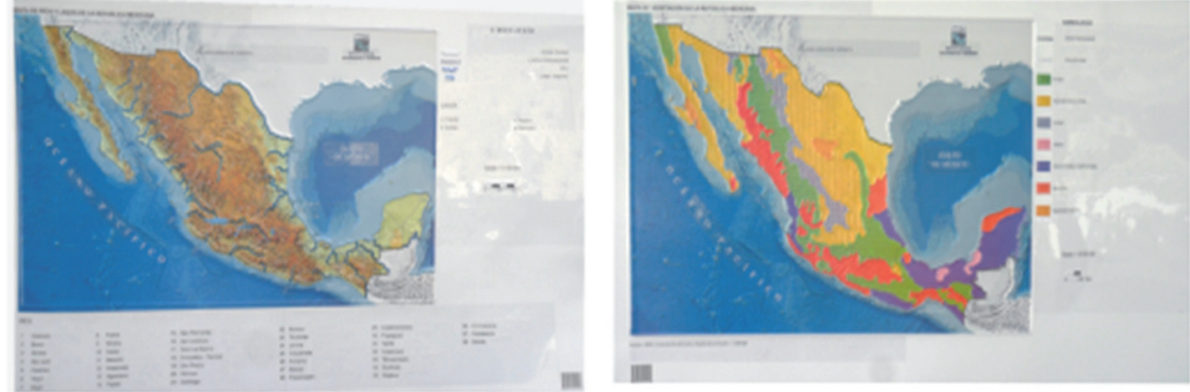

Mapa de ríos.

Mapa de vegetación.
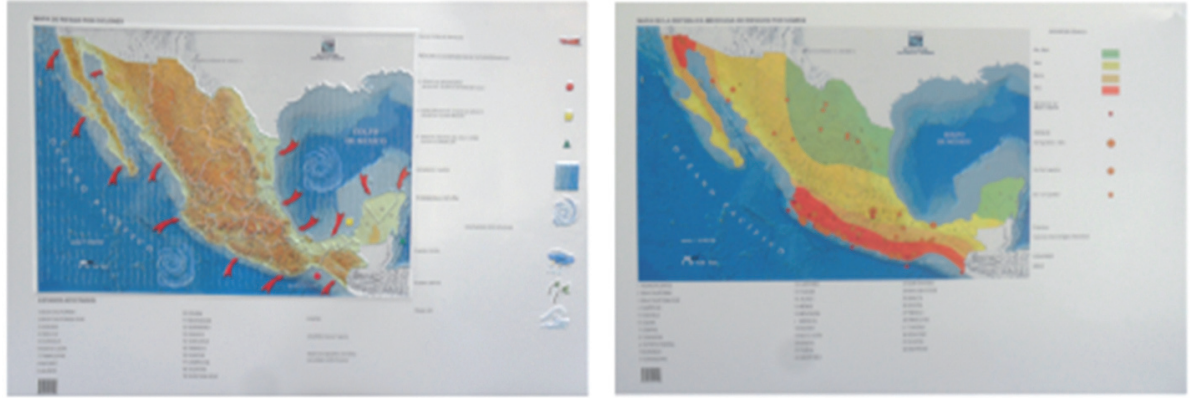

Mapa de ciclones.

Mapa de sismos.

Figura 27. Catálogo de mapas táctiles producidas en el INEGI, listos para su distribución. 


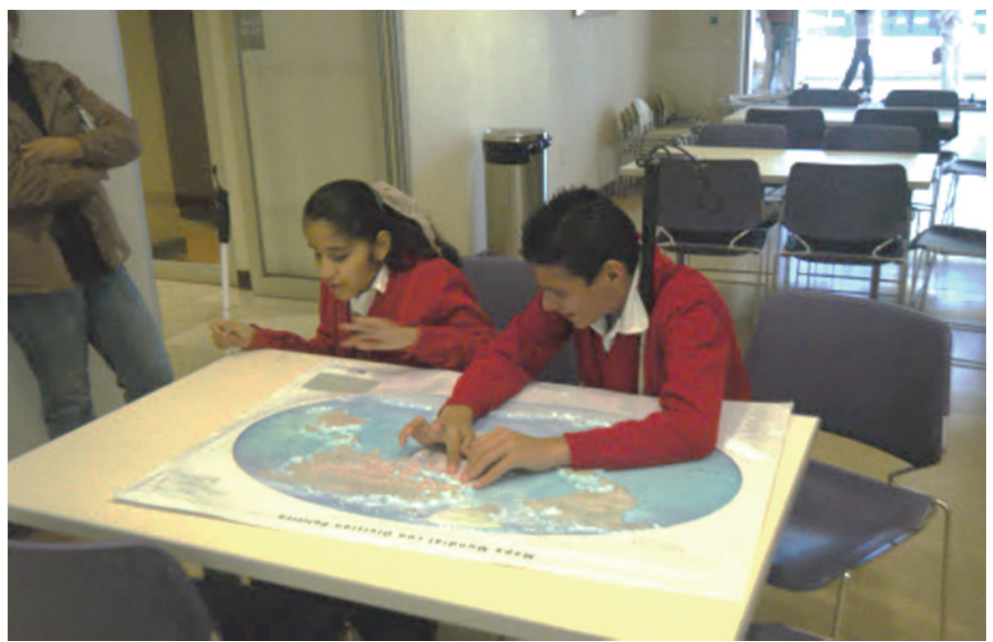

Figura 28. Alumnos utilizando mapa táctil mundial.

Para realizar la impresión de los rótulos del mapa, se elaboran listados de la tipografía en Word, se revisa la ortografía y posteriormente se convierte el texto a Braille mediante el software compatible con la impresora, enseguida se hace una impresión en papel braille opaco para su revisión, se verifica que éstos queden en los espacios del mapa, se revisa la ortografía; finalmente se manda la impresión de rótulos para el tiraje de mapas a elaborar (Figura 26).

La Dirección General de Geografía y Medio Ambiente cuenta con dos impresoras Braille para la producción de texto para mapas táctiles.

Una de las precauciones importantes que se deben tener con los mapas termoformados en PVC, es el de no exponerlo a los rayos solares por tiempo prolongado, ni a lugares o superficies calientes, ni dentro de los autos, ya que tiende a deformarse con las temperaturas altas.

\section{Recomendaciones para apoyar la lectura, interpretación y comprensión de un mapa táctil}

Si desde muy pequeños los niños invidentes tienen acceso a un mapa, aprenderán la forma de utilizarlo y les será una herramienta de gran utilidad para conceptualizar el espacio geográfico en su mente, "el mapa táctil permite realizar procesos mentales importantes para reconocer, identificar, comparar, analizar, transferir y complementar información". 2

2 Víctor Hugo Huentelemu, licenciado en Sociología; Teresa Barrientos, Educadora diferencial y trastornos de visión, Fundamentos para un sistema de enseñanza de mapas táctiles, <www.gsdidocs.org/gsdiconf/GSDI-9/slides/TS25.pdf>, consultado el 14 de noviembre del 2012. 
Para guiar a la persona ciega en el uso del mapa táctil, se recomienda que el profesor y los padres de familia conozcan de forma básica la temática, los elementos y la información marginal del mapa y así puedan explicar su contenido y significado de los símbolos que la persona invidente percibirá mediante el tacto. La comprensión de la información podría ser lenta dependiendo de la información del mapa y el tiempo que el usuario necesita para conceptualizar el tema.

Por ejemplo, se podrá comprender más fácil un mapa de climas que un mapa de suelos, porque la persona invidente conoce lo que es caliente, lo que es frío y lo que es templado, porque lo ha experimentado con las estaciones del año, o con los cambios del tiempo en cuanto a temperatura y fenómenos meteorológicos se refiere.

En cambio comprender un tipo de suelo, su textura, color, características físicas, etc., requerirá que se le explique, que se le brinde mayor información y que toque diferentes texturas de varios tipos de suelos para comprender la diferencia entre ellos.

Para la comprensión de la información se recomienda documentarse al menos en el nivel básico sobre la temática del mapa, así como realizar consultas en los sitios web, se sugiere consultar la página del Instituto Nacional de Estadística y Geografía (INEGI) en <www.inegi.org.mx $>$ y otros sitios nacionales e internacionales, para obtener información y conceptos sobre lo que es un mapa, información marginal, escala, país, fronteras o límites, división política, límites geoestadísticos, topografía, coordenadas, terreno, fisiografía, relieve, provincias fisiográficas, llanuras, mesetas, sierras, barrancas, suelos, ríos, arroyos, lagos, lagunas, presas, climas, ciclones, sismos, vegetación, océanos, mares, golfos, ciudad, localidad, manzana, calles, servicios urbanos, entre otros conceptos geográficos.

\section{Mapas elaborados por el Instituto Nacional de Estadística, Geografía e Informática}

1. Mapa mundial con división política

2. Mapa de límites geoestadísticos de la República Mexicana

3. Mapa de suelos de la República Mexicana

4. Mapa de vegetación de la República Mexicana

5. Mapa de climas de la República Mexicana

6. Mapa de regiones fisiográficas de la República Mexicana

7. Mapa de ríos de la República Mexicana

8. Mapa de ciclones de la República Mexicana

9. Mapa de sismos de la República Mexicana

10. Mapa de la ciudad de San Luis Potosí, Soledad de Graciano Sánchez

11. Mapa estatal de San Luis Potosí

12. Mapa urbano de Pachuca de Soto

13. Mapa estatal de Hidalgo 


\section{Experiencias}

Cuando se inició el trabajo de mapas táctiles para ciegos, tuvimos varias complicaciones tanto en su elaboración como en la interpretación por personas ciegas, tales como rasgos muy juntos que confundían al usuario, símbolos difíciles de diferenciar mediante el tacto, escritura no leíble en algunas palabras debido a que se realizaba mediante el mismo termoformado, por lo que algunos puntos salían planos, o no tenían altura uniforme.

No se contaba con personal que leyera la escritura Braille, ante la necesidad y el entusiasmo por el proyecto, el personal se capacitó por cuenta propia.

La elaboración de los moldes se complicó, ya que se carecía de experiencia en diseñar artísticamente los rasgos a representar, y en el manejo de los materiales como el yeso, el barro, la cera y el cartón. Se recurrió a la capacitación, a la selección de personal con habilidades en estas actividades y a experimentar para lograr poco a poco resultados.

Actualmente no se tienen datos estadísticos que indiquen el grado de aceptación y utilidad de estos mapas, sin embargo desde el año 2010, se tiene el apoyo de profesores de escuelas primarias que tienen a cargo alumnos ciegos, hacen recomendaciones, para ser consideradas en el diseño y representación de la información en alto y bajo relieve, así como la inclusión de la escritura Braille; frecuentemente se tienen requerimientos de mapas, los cuales son proporcionados de forma gratuita por el INEGI.

Se ha contemplado continuar con este proyecto, coordinadamente con autoridades de la Secretaría de Educación Pública, en el área de educación especial, donde se considera la enseñanza escolar para ciegos.

\section{Conclusiones}

El mapa táctil debe diseñarse cuidadosamente, seleccionando la información y textos a representar, revisando los espacios para rotular la escritura Braille, teniendo en cuenta que esta ocupa más espacio que la escritura visual.

Para la representación de la información, se debe seleccionar y representar símbolos que puedan ser reproducidos en la elaboración del molde, símbolos que no sean complicados, fáciles de comprender mediante el tacto de los dedos de la mano.

La elaboración de los mapas táctiles en color con letra visual y letra en Braille, permite al profesor, padres de familia, compañeros y amigos de la persona ciega, apoyarle en la enseñanza, tener la interacción y fortalecer los conocimientos geográficos.

El modelado del terreno en plastilina, y la elaboración del contramolde, son subprocesos importantes porque de ellos depende la calidad del molde donde se termoforma el mapa, se requieren conocimientos y habilidades de modelado artístico, 
interpretación y análisis de curvas de niveles y elaboración de moldes en yeso, ya que se necesita un molde en resina bien elaborado, que refleje los rasgos del terreno a la escala de representación, que tenga la dureza y resistencia para aguantar el calor y succión del vacío.

El equipo de termoformado con que cuenta el INEGI, ha sido diseñado especialmente para la producción de mapas en relieve y se compone de prensas para sostener el mapa, cámara de calor para dar elasticidad al material plástico y equipo de vacío y enfriamiento que conjuntamente con el molde permite moldear el mapa.

El contar con impresoras Braille para elaborar la tipografía, facilita la rotulación de los rasgos del terreno, obteniéndose un texto de calidad que ayuda a la persona ciega a la lectura de la información del mapa.

Las recomendaciones para apoyar la lectura, interpretación y comprensión del tema en el mapa táctil, ayuda a la impartición y a una más rápida asimilación de los conocimientos por personas ciegas o débiles visuales.

\section{Bibliografía}

Huentelemu, V.H. y Barrientos, T., "Fundamentos para un sistema de enseñanza de mapas táctiles". Disponible en: <www.gsdidocs.org/gsdiconf/GSDI-9/slides/TS 25.pdf $>$, consultado el 14 de noviembre del 2012.

Robinson, A.; Sale, R.D.; Morrison, J.L. y Muehrcke, P.C., Elementos de cartografia, Ed. Omega, Barcelona, España, 1987. 